\title{
Exoskeleton acceptance and its relationship to self-efficacy enhancement, perceived usefulness, and physical relief: A field study among logistics workers
}

\author{
Sandra M. Sied1* (D) and Martina Mara (D) \\ LIT Robopsychology Lab, Johannes Kepler University Linz, Linz, Austria \\ *Corresponding author. Email: sandra.siedl@jku.at
}

Received: 10 January 2021; Revised: 21 June 2021; Accepted: 09 August 2021

Keywords: Exoskeleton; Psychological Well-being; Field Experiment

\begin{abstract}
Objective: This field study aimed to explore the effects of exoskeleton use on task-specific self-efficacy beliefs of logistics workers and to relate these effects to usefulness perceptions and technology acceptance.

Background: A growing number of industrial companies have shown interest in having employees wearing exoskeletons to support their physical health. However, psychological consequences of exoskeleton use and mechanisms associated with workers' acceptance or rejection of exoskeletons are not yet sufficiently understood.

Methods: A total of 31 logistics workers of a vehicle manufacturing company reported on their work-related selfefficacy, that is, how capable they felt of performing tasks related to their job well, before partaking in half-hour trials of a passive lift-assistive exoskeleton (Laevo V2.5) during their normal work. Afterward, they completed a questionnaire on their exoskeleton-supported self-efficacy and indicated how useful they found the exoskeleton, how much physical relief they felt from wearing it, and how willing they were to continue with its use.

Results: Overall, wearing the exoskeleton did not lead to increased work-specific self-efficacy. However, indications of interaction effects were found between baseline self-efficacy, perceived physical relief, and perceived usefulness in such a way that workers who experienced the exoskeleton as more strain-relieving or more useful were also more likely to report a post-trial growth in their self-efficacy beliefs. A positive change in self-efficacy, in turn, was associated with a greater willingness to further use the exoskeleton at the workplace.
\end{abstract}

\section{Introduction}

Exoskeletons for human bodies follow the overarching idea of stabilizing their wearers and reducing musculoskeletal injuries. Tightly coupled to the human body, they are made for external human power assistance or augmentation (Lee et al., 2012). Usually, two types of exoskeletons are distinguished: Whereas active exoskeletons integrate actuators to actively amplify human strength, passive exoskeletons work without any actuators, but use springs, cable controls, and special fabric structures to support the human body and redistribute energy harvested from a person's previous motions (Gopura and Kiguchi, 2009; Bosch et al., 2016).

To date, only a handful of active exoskeletons are commercially available for industrial applications (e.g., Cray X by German Bionic or Ironhand by Bioservo). The vast majority of available exoskeletons for industry still are passive systems. Although even the comprehensive and widespread implementation of 
passive exoskeletons in corporate working environments can be regarded as still in its infancy, their practical applications are strongly increasing (Rupal et al., 2017; Amandels et al., 2019). Car manufacturing companies in particular have already started testing passive exoskeletons for their employees and implementing them in workplaces, as demonstrated by case reports from recent years (e.g., Spada et al., 2017; Hensel and Keil, 2019).

Nevertheless, empirical exoskeleton field studies that investigate the conditions under which workers would actually be willing to wear exoskeletons during their working time are scarce. More precisely, little is known about the psychological determinants and the effects of using exoskeletons in the workplace. This is where the present research comes into play. Against the background of Technology Acceptance literature and Self-Efficacy Theory (Bandura, 1977, 1999), we examined, on site in a vehicle manufacturing company, how exoskeleton use affects task-specific self-efficacy (TSSE) beliefs of logistics workers. We found this to be particularly important because self-efficacy beliefs are considered an important personal resource for well-being in the workplace (Heuven et al., 2006; Barbaranelli et al., 2018; Hallak et al., 2018). We were interested in how exoskeleton-related changes in self-efficacy beliefs, perceived usefulness, and physical relief are interrelated with the workers' willingness to make further use of the exoskeleton.

To the best of our knowledge, this is the first field study that connects the psychological construct of self-efficacy to user acceptance of exoskeletons and that applies a repeated-measures design around real exoskeleton trials in the highly relevant field of industrial logistics. Rather than looking at objective performance measures, we decided to focus on subjective experiences and internal cognitions of workers and thus wanted to contribute to establishing more user-centric approaches in exoskeleton research.

\section{Health Benefits of Exoskeletons}

Regarding the nature of work tasks, research repeatedly identified manual handling tasks, such as material handling or order picking, as potentially relevant for exoskeleton application (Theurel et al., 2018; Toxiri et al., 2019). Particularly where work tasks cannot be fully automated or where robots are too bulky and inflexible, manual handling tasks like lifting, stacking, and carrying heavy objects and working in awkward positions remain on the agenda (Eurofound, 2019; Peters and Wischniewski, 2019). However, repeated disadvantageous movements and postures place significant strain on the human body and make workers in logistics likely to suffer from musculoskeletal disorders, that is, limitations in the human musculoskeletal system by repetitive-strain injuries or pain (Cole and Grimshaw, 2003; de Looze et al., 2016; Bergmann et al., 2017). More precisely, they comprise physical complaints localized in specific anatomical areas like the upper limbs, the neck, the upper and middle part of the spine, and in the lumbar region (de Kok et al., 2019). In the European Union, for example, roughly $60 \%$ of workers struggle with musculoskeletal disorders (de Kok et al., 2019).

Previous research on health effects of passive exoskeletons suggests that they can indeed reduce the strain on typically affected muscle groups and thus bring effective physical support and relief for workers (Kim et al., 2018; Theurel et al., 2018). For instance, if a person bends forward, the released energy by a passive exoskeleton may support holding a position with less physical effort or it assists returning to an upright position while lifting an object from the ground (de Looze et al., 2016). However, since exoskeletons - unlike other industrial assistance tools - are unique in their requirement to be worn on the body and, to some degree, also impact their users' physical flexibility, conditions of user acceptance of exoskeletons call for urgent attention. Without the willingness of workers to use exoskeletons regularly during work, they will not be able to unfold their health-promoting potential. Therefore, knowing about the interplay of aspects influencing technology acceptance is crucial to understand what prompts workers to continue exoskeleton use at their workplace (Rahman et al., 2016; Latikka et al., 2019). 


\section{Technology Acceptance and Exoskeleton Acceptance}

Technology acceptance can be described as an individual decision-making process that ultimately results in the use of a particular technology (Schade and Schlag, 2003). For the field of information technology, Dillon and Morris have defined user acceptance as "the demonstrable willingness within a user group to employ a technology for the tasks it is designed" (Dillon and Morris, 1996). The aims of technology acceptance research typically are to gain a better understanding of determinants and effects of technology use and, in a more application-oriented manner, also the elaboration of guidelines on the basis of which specific technologies can be designed for wider acceptance. For both objectives, it is necessary to understand how various influencing variables are related to each other (Mara and Meyer, forthcoming).

There are different theoretical approaches meant to disentangle the multivariate interdependendencies behind technology adoption. The Technology Acceptance Model (TAM) by Davis (1989) has established itself as one of the most widely known research models in this field (cf. Hornbæk and Hertzum, 2017). Originally intended for use in the software domain, various authors have adapted the TAM for new application contexts or added additional explanatory variables, resulting in a number of alternative theoretical models. These include, for example, the Unified Theory of Acceptance and Use of Technology (UTAUT by Venkatesh et al., 2003; UTAUT2 by Venkatesh et al., 2012), TAM2 (Venkatesh and Davis, 2000), TAM3 (Venkatesh and Bala, 2008), ALMERE for the context of socially assistive robots (Heerink et al., 2010), or AVAM for the area of autonomous vehicles (Hewitt et al., 2019).

The majority of these models identify pragmatic attributes of technology, that is, features related to effort and outcome, as key antecedents of technology acceptance (Hornbæk and Hertzum, 2017). Usefulness, as one of the central variables here, incorporates the benefits and the achievable performance enhancement that a person perceives or expects from using a particular technology (Kothgassner et al., 2013). Usability, that is, the degree of effort perceived or expected to use a system (as defined by Kothgassner et al. in the Technology Usage Inventory), is assumed to constitute a second central factor in shaping technology acceptance (operationalized as "ease of use" in TAM1-3 or as "effort expectancy" in UTAUT1-2). At the core of many models of Technology Acceptance, therefore, is the assumption that perceived usefulness and perceived usability are the primary drivers of stronger or weaker intentions to use a given technology, which — with recourse to Ajzen's Theory of Planned Behavior (Ajzen, 1985) should in turn determine the actual use of the system. Transferred to the field of exoskeletons, this would mean that it should matter how applicable and easy to use they seem to be against task-specific requirements and how much uplift in their job performance users can expect from wearing them.

As one of the first studies in the realm of exoskeletons, Elprama et al. (2020) investigated the acceptance of exoskeletons among 124 industrial workers by applying an adapted version of the UTAUT model from Dwivedi et al. (2017). They surveyed how participants thought about exoskeletons and their use in the workplace, however, no exoskeletons were tried out. Although the model managed to account for $75.6 \%$ of the variance in intention to use exoskeletons (with large effects of perceived ease of use and usefulness and a moderate effect of social influence), the study still involved pre-trial attitudes only. Kermavnar et al. (2021) demonstrate, in their review on 33 studies dealing with back support exoskeletons, that in addition to objective performance measurements, subjective user evaluations were also incorporated into some studies. Corresponding measures addressed changes in perceived exertion and physical comfort, wearing comfort, perceived usefulness, or adjustability. For example, passive exoskeletons were found to reduce local discomfort in the back while static bending but led to a higher discomfort perceived in the chest. Although the high variability in test designs, involved tasks, and exoskeletons used does not allow for universal conclusions, these studies have broadened the knowledge on effects that industrial exoskeletons may have on their users. However, with the exception of Baltrusch, Houdijk, van Dieën, and de Kruif(2020), self-efficacy beliefs remained largely unexplored in this context. Further, and despite the increasing amount of empirical work with a focus on exoskeleton acceptance (cf. Baltrusch et al., 2018; Hensel et al., 2018; Maurice et al., 2019; Elprama et al., 2020; Shore et al., 2020), only a handful of studies were conducted in a real-life context with an exoskeleton in application so far (cf. Graham et al., 2009; Amandels et al., 2019; Hensel and Keil, 2019; Motmans et al., 2019). 
In an automotive manufacturing context, which is also relevant to the present work, Graham et al. (2009), descriptively assessed user acceptance of a passive upper limb lift-assistance exoskeleton among 10 operators. They asked for effects on perceived muscle effort, wearing comfort, satisfaction with the level of support, and the scope of job inference after testing and found user acceptability to be generally high. Unfortunately, operationalizations and intercorrelations of the constructs remained unclear. By providing 30 workers with a Laevo V2.5 exoskeleton for 1-4 weeks (depending upon selected workplace), a field study of Hensel and Keil (2019) found a significant decline in intention to use from the start across the testing period. They reported significant correlations regarding perceived physical discomfort, wearing discomfort, and usability with intention to use the exoskeleton. Two further studies were performed in the workplace by using the Laevo exoskeleton V2.4 (Amandels et al., 2019) and V2.5 (Motmans et al., 2019). Amandels et al. (2019) involved nine participants for two consecutive $30 \mathrm{~min}$ periods (one with and one without the exoskeleton) after a 3-week trial. Participants rated their discomfort after each period (that was perceived higher when wearing the exoskeleton for the upper chest, back, and thighs) and evaluated their perception of the exoskeleton regarding attractiveness, efficiency, dependability, novelty, perspicuity (operationalized similarly to usability), and simulation. Ratings were reported to be neutral except a positive average rating on novelty. In the study of Motmans et al. (2019), 10 operators carried out an order picking task for $90 \mathrm{~min}$, each with and without the exoskeleton. The authors collected data on perceived exertion, comfort, adjustability, and effectivity (physical load, fatigue, and posture), but did not elaborate on exoskeleton acceptance though a good overall acceptance during work was mentioned.

\section{Self-Efficacy Beliefs as Psychological Resource}

Self-efficacy beliefs have been suggested as a key variable to study employees' well-being and behavior at work (Heuven et al., 2006; Rahman et al., 2016) and also appear to be a potential determinant of behavioral intentions to make use of exoskeletons (Baltrusch, Houdijk, van Dieën, and de Kruif, 2020).

The concept of self-efficacy originates from Bandura's Social Cognitive Theory (Bandura, 1999) and can be understood as the strength of conviction people have in their effectiveness or capabilty to perform a certain behavior in a goal-oriented manner (Bandura, 1977). Core to the definition of self-efficacy is that it does not refer to objective evaluations of how skillful or successful a person is, but to one's belief in oneself to succeed in specific situations or accomplish specific tasks. Given that this belief in one's own abilities can vary intraindividually depending on a person's recent mastery experiences, his or her emotional state, or situational specifics, self-efficacy is not regarded as a stable personal trait, but rather as a construct that can be changed and therefore also manipulated by interventions (Baltes, 1987; Barbaranelli et al., 2018).

In the broadest sense, the concept of self-efficacy refers to an individual's general self-efficacy, that is, one's self-belief to cope with a variety of demands in life (e.g., Chen et al., 2001). However, there also exist many more specific conceptualizations of self-efficacy dedicated to different tasks or technologies (Rahman et al., 2016). This is consistent with the suggestions of Bandura (2006) to operationalize selfefficacy as domain-specific construct in order to raise its predictive and explanatory value. As a consequence, various scales have been developed to measure individual self-efficacy beliefs in certain contexts, including such specifically related to job-related tasks (Abele et al., 2000), which are of interest for the present study.

Self-efficacy beliefs represent a significant personal resource in the work context that is considered as highly relevant not only for the actual performance but also for the well-being of employees (Barbaranelli et al., 2018; Hallak et al., 2018). Heuven et al. (2006), for example, found a positive influence of workrelated self-efficacy beliefs on well-being insofar as they moderated the relationship between emotional job demands and emotional dissonance, respectively emotional dissonance and work engagement. Furthermore, a study conducted by McDonald and Siegall (1992) provided evidence for a potential beneficial impact of technological self-efficacy on work satisfaction, commitment, work quality, and work quantity. 
Although the relevance of positive self-efficacy beliefs for different work-related goal variables is well supported empirically, little is known regarding the relation between passive exoskeleton usage and taskspecific self-efficacy in an occupational context. Since Baltrusch, Houdijk, van Dieën, and de Kruif (2020) provide first evidence for a link between wearing an exoskeleton and self-efficacy enhancement, we assumed that our exoskeleton field trials would positively affect workers' task-specific self-efficacy in a pre-post comparison. Considering that enhanced self-efficacy should be perceived as something desirable, we expected that an increase in self-efficacy would lead to greater intentions to keep using the exoskeleton. In light of the Technology Acceptance literature, we further predicted that the usefulness and usability attributed to the exoskeleton would also be positively associated with exoskeleton acceptance.

\section{Methods}

\section{Participants and Selection of Workplaces}

We conducted a field study with $N=42$ logistics workers of an Austrian manufacturer of firefighting vehicles (see Figure 1). In order to invite only participants for whom exoskeletons might be at all relevant, available data of a previously performed ergonomic workplace analysis in the logistics department of the company were reviewed. Furthermore, coordination meetings were held with workplace supervisors and with the occupational physician. In dialog with the company, several workplaces were then selected as fitting for trials of the Laevo exoskeleton. Overall, these workplaces were characterized by high levels of load placed on the workers' back, work tasks involving dynamic repositioning activities (repetitive symmetric and asymmetric lifting), and manual material handling. Additionally, the components handled varied considerably in terms of size, mass, and load.

After their recruitment, 42 logistics workers took part in the exoskeleton study during their regular working time and were asked to fill in a paper-and-pencil questionnaire before and after their exoskeleton trial. Data from 11 participants had to be excluded from statistical analyses, as they did not complete or failed to return the post-trial questionnaire used to evaluate participants' experience with the exoskeleton. Of these 11, six participants specified a lack of time as the main reason for not completing the evaluation questionnaire. Another five participants referred to a lack of fit of the provided exoskeleton for their executed work activity during the trial. For example, one person who worked in the goods receiving department, spent the entire test duration standing in front of a computer without performing any of the usual manual material handling operations due to a system problem.

The final sample comprised of $N=31$ employees aged 20-56 $(\mathrm{M}=35.42$ years, $\mathrm{SD}=10.90)$. Due to an inherently high proportion of men working in the logistics department of the company, more than $92 \%$ according to their own statement, the share of women participating in the study was, as expected, small ( $9.7 \%$ female, $90.3 \%$ male, and $0 \%$ nonbinary), though it does reflect the department's actual gender distribution. While $12.9 \%$ of participants reported to be slightly familiar with exoskeletons, mostly through media reports, $87.1 \%$ did not have any prior experience with this technology.

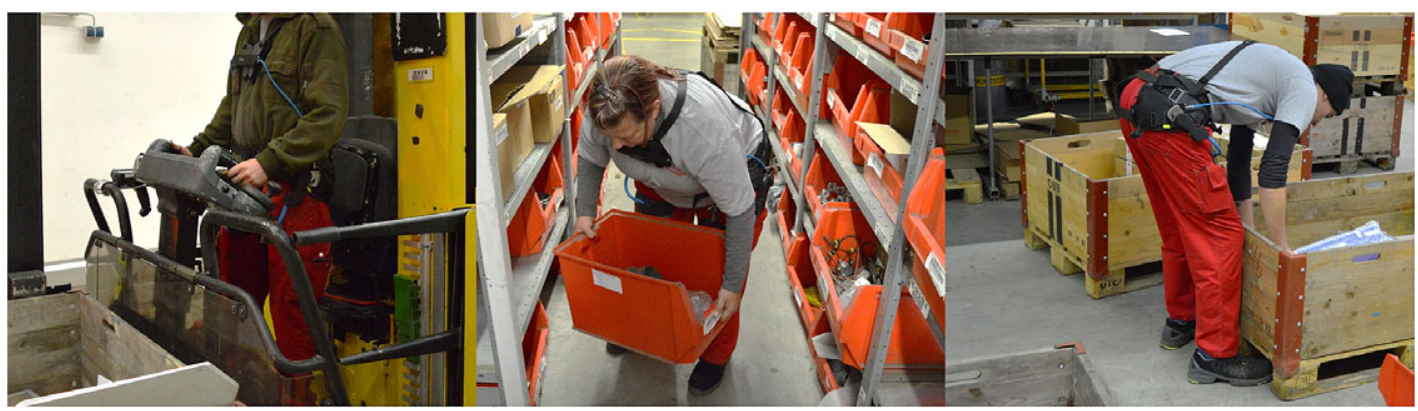

Figure 1. Field trial of passive exoskeleton Laevo V2.5 while stocking components and order picking. 
With respect to the distribution of workplaces, the final sample represented four different areas of logistics activity. Five participants were responsible for the receipt of goods from suppliers (WP \#1). They electronically registered incoming components and reallocated them from cargo carriers to defined boxes and places for storage mainly by manual lifting. A total of 14 participants performed order picking jobs (WP \#2) by collecting components in high rack storage (that typically involve far-reaching with lateral bending), middle section storage, and on ground level (that require taking and placing of material) or a mixture of storage areas. Due to overlapping responsibilities, one pair of participants was responsible not only for order picking but also inventory work, and another pair carried out order picking and storage work. Six workers responsible for packaging (WP \#3) received goods from their colleagues to pack them into boxes or by using other different kinds of appropriate packaging material for further transport. Since components strongly varied in their size and mass, there was not any standardized working height. By means of internal transport (WP \#4) such as forklifts and towing vehicles, four participants delivered material and components to their pre-determined destinations located in different production departments of the company, and regularly carried out manual reloading at the corresponding target destinations. Two allrounders who switched between the workplaces of order picking, receipt of goods, and packaging were also included in the sample.

\section{Procedure}

The exoskeleton trials took place at four different logistics sites directly in or in the immediate vicinity of the company's headquarters. In the course of three previously held and locally spread information events, all employees of the logistics department were invited to take part in our "exoskeleton trial and evaluation project." Employees were informed that their participation was voluntary and that they would be required to wear a passive trunk exoskeleton during regular task execution for at least $30 \mathrm{~min}$ on predefined days. We explained that participation would further include a short introduction on how to properly and safely use the exoskeleton as well as completing two questionnaires, a baseline questionnaire before testing (at $t_{1}$ ) and an evaluation questionnaire after testing (at $t_{2}$ ), all together taking about an hour (see Figure 2).

Before the start of their study participation, each worker gave his or her informed consent. The order of their actual study participation was randomized. At $t_{1}$, participants filled in the baseline questionnaire ${ }^{1}$ that included sociodemographics (e.g., gender, age, or mother tongue) and a scale on their task-specific selfefficacy belief. Further, they were asked about their previous experience with exoskeletons. The exoskeleton was then appropriately adjusted to the participant's body size. A short introduction into the correct use of the exoskeleton, its potential risks and available exit mechanisms followed. Subsequently, workers wore the exoskeleton directly at their workplace during regular task performance. After approximately $30 \mathrm{~min},{ }^{2}$ participants completed the evaluation questionnaire $\left(t_{2}\right)$. It required them, again, to report on task-specific

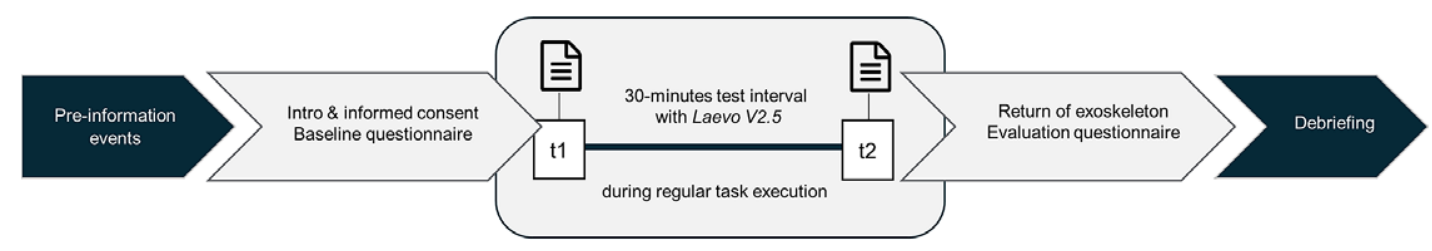

Figure 2. Overview of the field study procedure.

\footnotetext{
${ }^{1}$ Since the study was part of a larger-scale research project and also involved further research partners, questionnaires included additional measures (e.g., Questionnaire for Subjective Assessment of Workplace Exposure), which were not of interest for the current research questions and hence, are not reported here.

${ }^{2}$ In order to avoid an immediate termination of the work activity for workers, the exoskeleton was worn for a little longer than $30 \mathrm{~min}$ by some participants, resulting in minimal time deviations (single-digit range).
} 
self-efficacy beliefs. In addition, they rated the exoskeleton's usefulness and usability, and indicated how much physical relief it gave them and how much they were willing to adopt it at work.

\section{The Exoskeleton}

We used the Laevo V2.5 exoskeleton, a rigid passive trunk exoskeleton for industrial application, weighing about $2.2 \mathrm{~kg}$. As a market-ready back-assistive device, it is supposed to support lifting and forward bending activities and heavy workload manipulation at the workplace (Bosch et al., 2016; Voilqué et al., 2019). The exoskeleton consists of one pad on the anterior side of the chest, a back pad at the level of the pelvis and two shells on the thighs. Rigid stabilizing bars connect the chest pad with the pelvis belt and are adjunct to both upper leg components by running over a joint mechanism with spring-like characteristics on both sides of the pelvis. The system is worn with the pelvis belt around the waist and can be adjusted to the size of the wearer via the applied belts and the buckle and bar system. When bending forward, a supporting extension moment is created through the joint mechanism (Baltrusch et al., 2018), intended to transfer forces from the lower back to the chest and thighs pads. The chest pad rotates in the frontal plane of the trunk to allow for more flexible movements and to facilitate walking.

\section{Measures}

Our paper-and-pencil questionnaires ${ }^{3}$ included the following measures:

The scale to evaluate Task-Specific Self-Efficacy (TSSE) was adapted from Abele et al. (2000) and Rosen (2004), using four items ${ }^{4}$ and a 5-point response scale (from $1=$ not agree at all to $5=$ totally agree). The items used at $t_{1}$ and $t_{2}$ differed slightly, since $t_{2}$-items were adjusted to the experience throughout the exoskeleton trial. Example items are "I feel able to perform my job tasks comprehensively." and "I have confidence in my abilities and can thus calmly face task-related difficulties." at $t_{1}$, compared to "Assisted by the exoskeleton, I feel able to perform my job tasks comprehensively." and "Supported by the exoskeleton, I have confidence in my abilities and can thus calmly face task-related difficulties." at $t_{2}$ (see Appendix Table A1). The internal consistency of TSSE was good at both points in time with Cronbach's $\alpha_{t 1}=.75$ and $\alpha_{t 2}=.80$. The change in TSSE, referred to as TSSE diff $_{\text {in }}$ the following, was calculated by subtracting the baseline measurement score from the evaluation score reported after the exoskeleton trial $\left(\mathrm{TSSE}_{t 2}-\mathrm{TSSE}_{t 1}\right)$.

At $t_{2}$, Intention to Use (ITU) was assessed with the validated German Technology Usage Inventory (Kothgassner et al., 2013) (e.g., "I would use the exoskeleton.") on a 7-point scale (from $1=$ not agree at all to $7=$ very much agree). With Cronbach's $\alpha=.94$, the scale yielded very good reliability. Usability (Usab) and Usefulness (Usf) perceptions were measured by applying the same inventory and response format (Kothgassner et al., 2013). The Usability scale consisted of three items ("The application of the exoskeleton is easy to understand.", "Overall, the use of the exoskeleton is simple.", "Using the exoskeleton is complicated." $[R])$. Unfortunately, the index formed did not achieve sufficient reliability $(\alpha=.52) .{ }^{5}$ In contrast, the four items meant to measure Usefulness (e.g., "The use of the exoskeleton would make things more comfortable.") formed a highly reliable index, indicated by Cronbach's $\alpha=.91$. Perceived strain relief (Rel) was measured with the single item "How much strain relief did the system provide?" by means of a 5point scale (from $1=$ hardly any to $5=$ very much) (see Appendix Table A2 and A3).

\section{Results}

For analysis of our data, we used the statistics software SPSS (version 27) and the MEMORE macro for SPSS. The latter enables moderation analysis in two-instance repeated-measures designs, based on a

\footnotetext{
${ }^{3}$ The original language of the questionnaires was German. Sample items listed in this section were translated into English.

${ }^{4}$ Two items from the original scale have been excluded since they addressed motivational aspects without any possibility to adapt them to exoskeleton application.

${ }^{5}$ Since this scale was not reliable and since we also found no significant correlations with other variables explored in this study (see Table 1), we decided to exclude usability from further reports in this paper.
} 


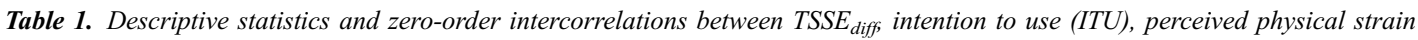
relief (Rel), usability (Usab), usefulness (Usf), age, and gender

\begin{tabular}{|c|c|c|c|c|c|c|c|c|c|c|}
\hline \multirow[b]{2}{*}{ Variable } & \multirow[b]{2}{*}{ M } & \multirow[b]{2}{*}{ SD } & \multirow[b]{2}{*}{$N$} & \multicolumn{7}{|c|}{ Correlations (Spearman's $\rho$ ) } \\
\hline & & & & $\mathrm{TSSE}_{\text {diff }}$ & ITU & Rel & Usab & Usf & Age & Gender \\
\hline $\mathrm{TSSE}_{\text {diff }}$ & -.31 & .88 & 31 & - & & & & & & \\
\hline ITU & 5.32 & 1.70 & 31 & $.43^{*}$ & - & & & & & \\
\hline Rel & 3.23 & 1.23 & 31 & $.48 * *$ & $.51 * *$ & - & & & & \\
\hline Usab & 6.17 & .97 & 31 & .17 & .28 & .24 & - & & & \\
\hline Usf & 4.96 & 1.51 & 31 & $.64 * * *$ & $.69 * * *$ & $.54 * *$ & $.45^{*}$ & - & & \\
\hline Age & 35.42 & 10.90 & 31 & -.19 & -.27 & -.13 & -.02 & -.13 & - & \\
\hline Gender & 1.10 & .30 & 31 & -.29 & .10 & -.03 & -.07 & -.04 & .21 & - \\
\hline
\end{tabular}

Note: $* p<.05, * * p<.01$, and $* * * p<.001$ (2-tailed); Gender was coded 1 for men and 2 for women; TSSE $_{\text {diff }}$ was calculated by TSSE ${ }_{t 2}-$ TSSE $_{t 1}$.

bootstrapping procedure (Montoya and Hayes, 2017; Montoya, 2019). Levels of significance were set at the standard value of $p<.05$. Most of the data was not normally distributed, partly due to rather high mean values (right-skewed distribution). A Shapiro-Wilk test also indicated that the assumption of normality was violated regarding most variables of interest. ${ }^{6}$ As a consequence, we ran nonparametric tests, for example, Spearman's rank-order correlation $(\rho)$ to analyze the strength of relationships between variables (see Table 1).

Initial zero-order correlations indicate that the workers' reported intention to use, which was used to operationalize exoskeleton acceptance in this study, was most strongly and positively associated with the perceived usefulness of the exoskeleton, $\rho=.69, p<.001$. Significant interconnections were also found with physical strain relief $(\rho=.51, p=.004)$ and post-trial self-efficacy enhancement as represented by $\operatorname{TSSE}_{\text {diff }}(\rho=.43, p=.016)$. Our analyses yielded no significant correlations between age or gender and any other variables of interest (all $p \mathrm{~s}>.05$ ).

In order to assess exoskeleton-induced changes in workers' TSSE beliefs, we calculated a difference score $\left(\mathrm{TSSE}_{\text {diff }}\right)$ by subtracting the values of TSSE ${ }_{t 1}$ from TSSE $_{t 2}$. Descriptively, self-efficacy means were lower in $t_{2}\left(\mathrm{TSSE}_{t 2}: \mathrm{M}=4.11, \mathrm{SD}=.74\right)$ than in $t_{1}\left(\mathrm{TSSE}_{t 1}: \mathrm{M}=4.42, \mathrm{SD}=.56\right)$. Following this, a Wilcoxon signed-ranks tests for repeated-measures analysis was performed to compare TSSE scores before $\left(t_{1}\right)$ and after $\left(t_{2}\right)$ the exoskeleton trial. A borderline significant difference was found $(T=98.50$, $z=-1.97, p=.049$ ) with a more than moderate effect size of $r_{\mathrm{TSSE}}=.35$ (cf. Rosenthal et al., 1994; Gignac and Szodorai, 2016). On average, pre-test self-efficacy scores $(\mathrm{Mdn}=4.50)$ exceeded post-trial scores $(\mathrm{Mdn}=4.25)$. Our initial assumption that wearing an exoskeleton in general would have a positive effect on TSSE beliefs was therefore not supported.

A closer look into the descriptive statistics on exoskeleton-induced changes in self-efficacy indicated that although a total of 18 participants seemed to experience a decrease, 13 workers also reported either a neutral or a positive effect of the exoskeleton on their perceived self-efficacy. Therefore, we tried to explore the mechanisms behind these apparently divergent perceptions. We used the MEMORE macro by Montoya and Hayes (2017), which allows for the analysis of continuous moderators in repeated-measures models, to test for potential moderator effects of perceived usefulness and perceived strain relief. Selfefficacy after the exoskeleton trial $\left(\operatorname{TSSE}_{t 2}\right)$ served as the $Y$ variable and baseline self-efficacy before the exoskeleton trial $\left(\mathrm{TSSE}_{t 1}\right)$ as the $X$ variable. The outcome variable $Y_{\text {diff }}$ was calculated automatically by the program (TSSE ${ }_{t 2}-\mathrm{TSSE}_{t 1}$ again). Either strain relief or perceived usefulness were inserted as the moderator variable $W$. The following results include $95 \%$ confidence intervals using 5,000 bootstrap samples.

Strain relief was found to significantly moderate the effect of exoskeleton usage on self-efficacy beliefs $(b=.39,95 \%$ CI $[.1588, .6182], t(29)=3.460, p=.0017)$. Thus, for each unit increase in perceived strain relief, there was a 0.39 unit increase in the difference in self-efficacy. Wearing the exoskeleton therefore seemed less beneficial for the self-efficacy of workers for whom the exoskeleton provided less physical

\footnotetext{
${ }^{6}$ Shapiro-Wilk test indicated that the scores were not normally distributed, except for age $(W[31]=.934, p=.057)$.
} 


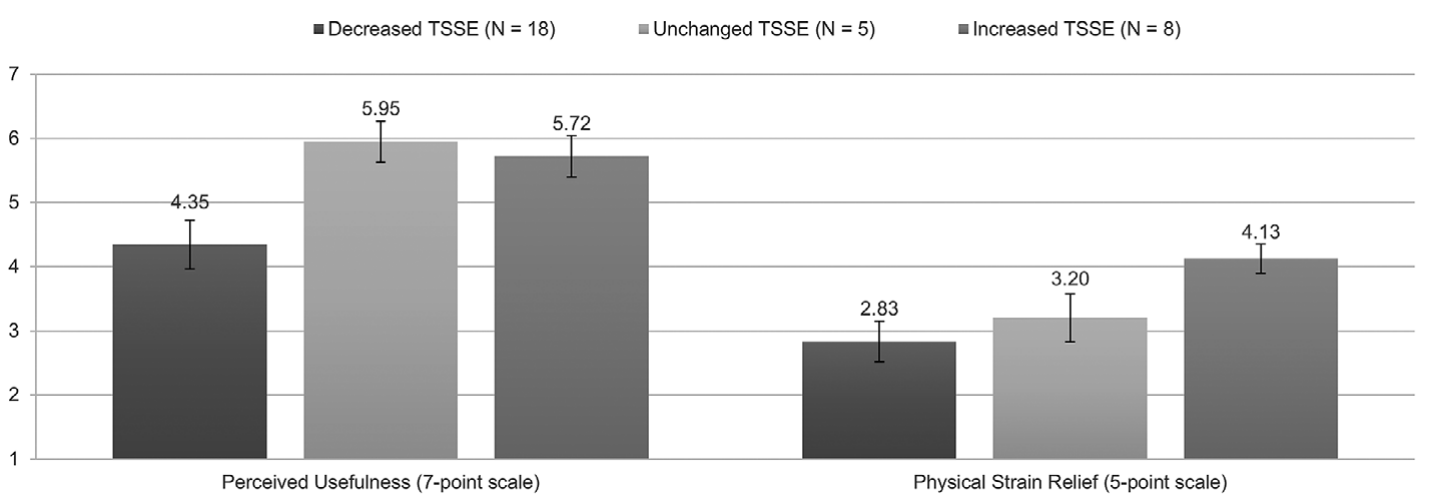

Figure 3. Explorative comparisons between worker groups with increased, unchanged, or decreased TSSE $\left(\mathrm{t}_{1} v \mathrm{v} . \mathrm{t}_{2}\right)$ in terms of perceived exoskeleton usefulness and physical strain relief.

relief. In addition, the perceived usefulness of the exoskeleton also moderated the technology's impact on differences in self-efficacy $(b=.42,95 \% \mathrm{CI}[.2625, .5732], t(29)=5.502, p<.001)$. Each unit increase in usefulness was connected to a 0.42 unit increase in self-efficacy enhancement from $t_{1}$ to $t_{2}$. While lower usefulness ratings of the exoskeleton were more likely to lead to a drop in a worker's self-efficacy belief, higher usefulness ratings were more likely to be associated with a positive change in self-efficacy as a function of wearing the exoskeleton.

Further, for exploratory purposes, we ran a Kruskal-Wallis test to compare worker groups with increased, unchanged, and decreased TSSE from $t_{1}$ to $t_{2}$ (i.e., a positive, zero, or negative TSSE $\mathrm{diff}_{\text {value, }}$ also see Figure 3). In line with the moderation analyses, results suggest that the three groups significantly differ in their perceived strain relief $(H(2)=6.12, p=.047)$ and their usefulness perceptions $H(2)=7.5$, $p=.024)$. Perceived strain relief was significantly higher for participants with increased TSSE $\left(\mathrm{Mdn}_{\text {rel. }}\right.$. pos. $=4.00)$ than for participants with unchanged TSSE $\left(\mathrm{Mdn}_{\text {rel.neutr. }}=3.00\right)$ and negative change in TSSE $\left(\mathrm{Mdn}_{\text {rel.neg. }}=3.00\right)$. Participants who perceived the exoskeleton as more useful recorded increased TSSE $\left(\mathrm{Mdn}_{\text {usf.pos. }}=5.62\right)$ respective unchanged TSSE $\left(\mathrm{Mdn}_{\text {usf.neutr. }}=6.00\right)$ compared to participants with decreased TSSE $\left(\mathrm{Mdn}_{\text {usf.neg. }}=4.63\right)$.

As previously mentioned, a positive effect of the exoskeleton on post-trial self-efficacy (TSSE $\left.\mathrm{diff}_{\text {iff }}\right)$ was in turn positively associated with the workers' behavioral intention to continue using the exoskeleton (ITU), indicated by Spearman's $\rho=.43, p=.016$.

\section{Discussion}

As a new technical aid, industrial exoskeletons are made for employees to support their health at the workplace. Considering the continuous technical progress and an increasing number of companies interested in exoskeleton application, it is not only relevant to investigate how they affect their wearers physically, but also the psychological antecedents and effects of their usage.

Support in our belief that we have the abilities to successfully accomplish our work tasks can be a valuable psychological resource, particularly when work demands are high (Heuven et al., 2006). Conversely, it can be detrimental if a technology supposed to help instead threatens these beliefs in ourselves. Since task-related self-efficacy has been largely neglected in research on industrial exoskeletons so far, we conducted a field study at four sites of an Austrian vehicle manufacturing company. Our focus was on gaining initial insights into the role that exoskeletons could play in the development of TSSE at the workplace. Moreover, we aimed to assess the interplay of changes in self-efficacy beliefs, pragmatic attributes of the exoskeleton (usefulness, usability, and physical relief), and behavioral intention to keep using the exoskeleton. We addressed logistics workers, who are a highly relevant target 
group that often faces strenuous work tasks and a resulting risk of musculoskeletal disorders (Frauenhofer, 2020).

On average, we found that wearing a passive trunk exoskeleton resulted in a (borderline significant) decrease in work-specific self-efficacy beliefs for our study participants. This opposed our assumption and previous empirical findings (Baltrusch, Houdijk, van Dieën, and de Kruif, 2020). Exploratory analyses of our data indicated that this may be associated with the fact that some workers in our sample felt constrained rather than relieved by the exoskeleton, or that its functions did not correspond well enough with their work tasks to be considered useful. However, for those workers who attributed greater usefulness to the exoskeleton, and also for those who perceived a greater physical relief from wearing it, the exoskeleton more likely led to an increase in TSSE beliefs, as supported by moderation analyses and group comparisons. Even though it was only under certain conditions that participants in our field study experienced a selfefficacy enhancement as a function of the exoskeleton, such an enhancement was in turn found to be positively associated with exoskeleton acceptance, that is, with greater intention to use the exoskeleton.

Taken together, the present research provides initial indications on determinants and effects of TSSE in the context of passive exoskeletons. We could show that self-efficacy constitutes an outcome variable affected by the use of exoskeletons at the workplace. However, this does not imply that the use of passive exoskeletons lets workers automatically gain more confidence in their abilities. Only at higher levels of perceived physical strain relief and usefulness, the TSSE of participants tended not to drop. Moreover, workers in this case were more willing to use the passive exoskeleton at work. Linked to the role of usefulness for technology acceptance, this latter finding is in line with TAM3 (Venkatesh and Bala, 2008) or UTAUT2 (Venkatesh et al., 2012).

With respect to these differential user responses, one may infer that exoskeletons provide no one-sizefits-all solution as this work assistive tool appears to be more suitable (i.e., useful and strain-relieving) for some workers than for others. This draws a connection to the larger ergonomic discourse on the healthprotecting potential of exoskeletons in general. Although passive exoskeletons are likely to reduce physical stress on defined body parts (Bosch et al., 2016; Koopman et al., 2019), there is still controversy whether exoskeletons can serve as an effective means to counteract the development of musculoskeletal complaints. This is due to the number of aspects to consider when using exoskeletons in the occupational context, as recently stated by the implementation recommendations of Steinhilber et al. (2020). Based on the findings of several empirical studies (Kim et al., 2018; Theurel et al., 2018; Alabdulkarim and Nussbaum, 2019) one of these recommendations addresses the required fit between the exoskeleton's support function and the nature and sequence of work activities as a precondition for effective load reduction. Also, in terms of exoskeleton-related user perceptions, there is evidence that a good fit between the exoskeleton applied and work task characteristics plays a pivotal role in this context (Siedl et al., 2021). As opposed to laboratory conditions, a major challenge of working situations in dynamic logistics environments is the inherently existing bundle of different work activities in particular workplaces and their recurrence in certain periodic or aperiodic time intervals. While for some of these work activities users might perceive support from the exoskeleton at hand, this might not be true for others (Baltrusch et al., 2018; Koopman et al., 2020). Since individual work tasks often cannot be strictly delimitated from other nonsupporting or even distracting activities, this brings the risk of a perceived overall misfit between exoskeleton and the respective workplace. In the present study, we had to deal with a relatively high dropout of participants, which can be partially attributed to the aforementioned circumstances and, concurrently, brings up new questions regarding perceived relative losses versus gains in terms of fit. This also comes with the requirement to sufficiently know about the concrete conditions under which exoskeletons are perceived useful and strain-relieving by whom. For example, TAM3 suggests variables like system image or output quality that are expected to influence perceived usefulness and technology acceptance (Venkatesh and Bala, 2008). Moreover, further research indicates that the physical health state of workers (e.g., presence of low back pain) can shape the "picture of usefulness" and impact behavioral adoption of exoskeletons (Baltrusch, Houdijk, van Dieën, van Bennekom, and de Kruif, 2020).

At the same time, experiences of one's own mastery and physiological feedback given by the human body are sources regarded to determine self-efficacy judgments (Bandura, 1977). Our study could 
corroborate this by finding a moderation effect of subjectively experienced strain relief on exoskeletoninduced changes in self-efficacy. However, questions concerning other factors (e.g., vicarious learning experiences as a social influence component) that are supposed to impact TSSE when using exoskeletons at the workplace remain unanswered. These aspects could represent an interesting option for future research designs, which not least would allow for drawing a more holistic picture of the interrelationships between variables and overcome limitations of the present study.

Besides the contributions of our study, we would also like to acknowledge some limitations and suggest potential starting points for future research. Despite participation of workers from four different logistics sites, the field study took place in a single company and involved only a relatively small number of participants. Although field studies in practical settings - due to the time and effort required of the practice partner and related trade-offs that must be made by the scientific partner-often involve even smaller or similar numbers of participants (Graham et al., 2009; Amandels et al., 2019; Hensel and Keil, 2019; Motmans et al., 2019; Smets, 2019), it must be recognized that with this comes limited statistical power. We therefore encourage careful interpretation of our results, in particular those regarded to be borderline significant.

Also, as only one specific type of passive exoskeleton was used in the present field study, we caution readers against generalizing the findings too broadly. Our decision to keep the exoskeleton model constant aimed at causally linking its use to potential changes in TSSE. To allow for a greater generalizability of results, studies with similar research questions could be conducted with other passive and active exoskeleton devices.

Although the proportion of female participants in our trials almost equaled gender distribution in the logistics department across the study company, the predominantly male composition of our sample limited investigating the influence of gender - particularly the perceptions of females - on work TSSE and intention to use. But as we know that males and females may have differential preferences regarding types of exoskeletons (Siedl et al., 2021), it is not clear whether the specific passive exoskeleton used in our trials would have been perceived in the same way.

A further limitation to be addressed refers to the application of a single item to measure experienced strain relief. Although the applied item allowed for a precise statement and was easy to understand in the context of corporate logistics, it still lacks reliability that limits its explanatory power.

In an attempt to trade off comprehensiveness and accuracy of the field study design optimally against parsimony and cost, an observable 30-min test interval was set. We supposed that 30-min trials would be sufficient for novice users to get an initial yet experience-based impression of the exoskeleton's functionality. This decision was also influenced by the lack of significant differences in exoskeleton acceptance across different test durations (ranging from 0.5 to $7 \mathrm{hr}$ ) indicated by an earlier field study (Siedl et al., 2021). However, this approach did not allow for exploring long-term effects associated with work TSSE and technology acceptance. Future research is encouraged to carry out longitudinal randomized control trials by conducting several measurements spread over a longer period of time.

\section{Conclusion}

Results of our field study with industrial logistics workers suggest a positive association between exoskeleton acceptance and technology-induced self-efficacy beliefs, whereby the latter were found to be moderated by strain relief capacity and usefulness attributed to the exoskeleton. The fact that the selfefficacy beliefs of our exoskeleton testers only increased under specific conditions indicates that industrial exoskeletons are not a one-size-fits-all technology. In practice, a good fit between exoskeleton, user, and work task characteristics must be targeted in order to achieve positive effects on the well-being of employees and their health. Here, the belief in one's self-efficacy not only constitutes an important psychological resource for employees, but it also seems to be associated with their willingness to make use of new assistive technologies. Taken together, we believe that our research provides novel evidence for the relevance of integrating further psychological constructs in a more human-centered evaluation of exoskeletons in real-life working environments. 
Acknowledgment. We would like to thank the manufacturing company and logistics workers for taking part in our study.

Funding Statement. This research was supported by the Austrian Research Promotion Agency (FFG—Nos. 861519 and 880563 ).

Competing Interests. The authors declare no competing interests exist.

Authorship Contributions. Study conceptualization, S.M.S., M.M.; Data gathering, S.M.S.; Statistical analysis, S.M.S., M.M.; Writing — original draft, S.M.S.; Draft refinement, S.M.S, M.M. All authors approved the final submitted manuscript.

Data Availability Statement. Data is available online under https://osf.io/vc56n/?view_only=909ca9f08c0f43b09 de $7 \mathrm{c} 2 \mathrm{~d} 08608 \mathrm{~d} 254$.

Ethical Statement. The authors assert that all procedures contributing to this work comply with the ethical standards of the relevant national and institutional committees on human experimentation and with the Helsinki Declaration of 1975, as revised in 2008.

\section{References}

Abele AE, Stief M and Andrä MS (2000) Zur ökonomischen Erfassung beruflicher Selbstwirksamkeitserwartungen-Neukonstruktion einer BSW-Skala. Zeitschrift für Arbeits-und Organisationspsychologie 44(3), 145-151.

Ajzen I (1985) From intentions to actions: A theory of planned behavior. In Kuhl J and Beckmann J (eds), Action Control: From Cognition to Behavior. Berlin: Springer, pp. 11-39. https://doi.org/10.1007/978-3-642-69746-3.

Alabdulkarim S and Nussbaum MA (2019) Influences of different exoskeleton designs and tool mass on physical demands and performance in a simulated overhead drilling task. Applied Ergonomics 74, 55-66. https://doi.org/10.1016/j. apergo.2018.08.004.

Amandels S, Eyndt HOH, Daenen L and Hermans V (2019) Introduction and testing of a passive exoskeleton in an industrial working environment. In Bagnara S, Tartaglia R, Albolino S, Alexander T and Fujita Y (eds), Advances in Intelligent Systems and Computing. Proceedings of the 20th Congress of the International Ergonomics Association (IEA 2018) (Vol. 820). Cham: Springer International Publishing, pp. 387-392. https://doi.org/10.1007/978-3-319-96083-8_51.

Baltes PB (1987) Theoretical propositions of life-span developmental psychology: On the dynamics between growth and decline. Developmental Psychology 23(5), 611-626. https://doi.org/10.1037/0012-1649.23.5.611.

Baltrusch SJ, Houdijk H, van Dieën JH and de Kruif AJ (2020) Passive trunk exoskeleton acceptability and effects on selfefficacy in employees with low-back pain: A mixed method approach. Journal of Occupational Rehabilitation 31, $129-141$. https://doi.org/10.1007/s10926-020-09891-1.

Baltrusch SJ, Houdijk H, van Dieën JH, van Bennekom CA and de Kruif AJ (2020) Perspectives of end users on the potential use of trunk exoskeletons for people with low-back pain: A focus group study. Human Factors 62(3), 365-376. https://doi.org/ $10.1177 / 0018720819885788$.

Baltrusch SJ, van Dieën JH, van Bennekom CAM and Houdijk H (2018) The effect of a passive trunk exoskeleton on functional performance in healthy individuals. Applied Ergonomics 72, 94-106. https://doi.org/10.1016/j.apergo.2018.04.007.

Bandura A (1977) Self-efficacy: Toward a unifying theory of behavioral change. Psychological Review 84(2), 191-215. https:// doi.org/10.1037/0033-295X.84.2.191.

Bandura A (1999) Social cognitive theory: An agentic perspective. Asian Journal of Social Psychology 2(1), 21-41. https://doi.org/ 10.1111/1467-839X.00024.

Bandura A (2006) Guide for constructing self-efficacy scales. In Pajares F and Urdan T (eds), Self-Efficacy Beliefs of Adolescents. Greenwich, CT: Information Age, pp. 307-337.

Barbaranelli C, Fida R, Paciello M and Tramontano C (2018) 'Possunt, quia posse videntur': They can because they think they can. Development and validation of the work self-efficacy scale: Evidence from two studies. Journal of Vocational Behavior 106, 249-269. https://doi.org/10.1016/j.jvb.2018.01.006.

Bergmann A, Bolm-Audorff U, Krone D, Seidler A, Liebers F, Haerting J, Freiberg A and Unverzagt S (2017) Occupational strain as a risk for hip osteoarthritis: A systematic review of risk assessment. Deutsches Ärzteblatt International 114(35-36), 581-588. https://doi.org/10.3238/arztebl.2017.0581.

Bosch T, van Eck J, Knitel K and de Looze M (2016) The effects of a passive exoskeleton on muscle activity, discomfort and endurance time in forward bending work. Applied Ergonomics 54, 212-217. https://doi.org/10.1016/j.apergo.2015.12.003.

Chen G, Gully SM and Eden D (2001) Validation of a new general self-efficacy scale. Organizational Research Methods 4(1), 62-83. https://doi.org/10.1177/109442810141004.

Cole MH and Grimshaw PN (2003) Low back pain and lifting: A review of epidemiology and aetiology. Work 21(2), $173-184$.

Davis FD (1989) Perceived usefulness, perceived ease of use, and user acceptance of information technology. MIS Quarterly 13, 319-340. https://doi.org/10.2307/249008.

de Kok J, Vroonhof P, Snijders J, Roullis G, Clarke M, Peereboom K, van Dorst P and Isusi I (2019) Work-Related Musculoskeletal Disorders: Prevalence, Costs and Demographics in the EU. European Risk Observatory Report. Luxembourg: European Agency for Safety and Health at Work - EU-OSHA. https://doi.org/10.2802/66947. 
De Looze MP, Bosch T, Krause F, Stadler KS and O'Sullivan LW (2016) Exoskeletons for industrial application and their potential effects on physical work load. Ergonomics 59(5), 671-681. https://doi.org/10.1080/00140139.2015.1081988.

Dillon A and Morris MG (1996) User Acceptance of New Information Technology: Theories and Models. Medford, NJ: Information Today.

Dwivedi YK, Rana NP, Jeyaraj A, Clement M and Williams MD (2017) Re-examining the unified theory of acceptance and use of technology (UTAUT): Towards a revised theoretical model. Information Systems Frontiers 21, 719-734. https://doi.org/ 10.1007/s10796-017-9774-y.

Elprama SA, Vannieuwenhuyze JT, De Bock S, Vanderborght B, De Pauw K, Meeusen R and Jacobs A (2020) Social processes: What determines industrial workers' intention to use exoskeletons? Human Factors 62(3), 337-350. https://doi.org/ 10.1177/0018720819889534.

Eurofound (2019) Working Conditions and Workers' Health. Luxembourg: Publications Office of the European Union. https:// doi.org/10.2806/909840.

Frauenhofer (2020) Exoskelette in Produktion Und Logistik. Grundlagen, Morphologie Und Vorgehensweise Zur Implementierung. Wien: Fraunhofer Austria Research GmbH.

Gignac GE and Szodorai ET (2016) Effect size guidelines for individual differences researchers. Personality and Individual Differences 102, 74-78. https://doi.org/10.1016/j.paid.2016.06.069.

Gopura RARC and Kiguchi K (2009) Mechanical designs of active upper-limb exoskeleton robots: State-of-the-art and design difficulties. In 2009 IEEE International Conference on Rehabilitation Robotics. Kyoto: IEEE, pp. 178-187. https://doi.org/ 10.1109/ICORR.2009.5209630.

Graham RB, Agnew MJ and Stevenson JM (2009) Effectiveness of an on-body lifting aid at reducing low back physical demands during an automotive assembly task: Assessment of EMG response and user acceptability. Applied Ergonomics 40(5), 936-942. https://doi.org/10.1016/j.apergo.2009.01.006.

Hallak R, Assaker G, O'Connor P and Lee C (2018) Firm performance in the upscale restaurant sector: The effects of resilience, creative self-efficacy, innovation and industry experience. Journal of Retailing and Consumer Services 40, 229-240. https:// doi.org/10.1016/j.jretconser.2017.10.014.

Heerink M, Kröse B, Evers V and Wielinga B (2010) Assessing acceptance of assistive social agent technology by older adults: The Almere model. International Journal of Social Robotics 2(4), 361-375. https://doi.org/10.1007/s12369-010-0068-5.

Hensel R and Keil M (2019) Subjective evaluation of a passive industrial exoskeleton for lower-back support: A field study in the automotive sector. IISE Transactions on Occupational Ergonomics and Human Factors 7(3-4), 213-221. https://doi.org/ 10.1080/24725838.2019.1573770.

Hensel R, Keil M, Mücke B and Weiler S (2018) Chancen und Risiken für den Einsatz von Exoskeletten in der betrieblichen praxis. ASU 53, 654-661.

Heuven E, Bakker AB, Schaufeli WB and Huisman N (2006) The role of self-efficacy in performing emotion work. Journal of Vocational Behavior 69(2), 222-235. https://doi.org/10.1016/j.jvb.2006.03.002.

Hewitt C, Politis I, Amanatidis T and Sarkar A (2019) Assessing public perception of self-driving cars: The autonomous vehicle acceptance model. In Proceedings of the 24th International Conference on Intelligent User Interfaces. New York: ACM, pp. 518-527. https://doi.org/10.1145/3301275.3302268.

Hornbak K and Hertzum M (2017) Technology acceptance and user experience: A review of the experiential component in HCI. ACM Transactions on Computer-Human Interaction (TOCHI) 24(5), 1-30. https://doi.org/10.1145/3127358.

Kermavnar T, Vries AW, Looze MP and O'Sullivan LW (2021) Effects of industrial back-support exoskeletons on body loading and user experience: An updated systematic review. Ergonomics 64, 685-711. https://doi.org/10.1080/00140139.2020.1870162.

Kim S, Nussbaum MA, Esfahani MIM, Alemi MM, Alabdulkarim S and Rashedi E (2018) Assessing the influence of a passive, upper extremity exoskeletal vest for tasks requiring arm elevation: Part I-“expected" effects on discomfort, shoulder muscle activity, and work task performance. Applied Ergonomics 70, 315-322. https://doi.org/10.1016/j.apergo.2018.02.025.

Koopman AS, Kingma I, de Looze MP and van Dieën JH (2020) Effects of a passive back exoskeleton on the mechanical loading of the low-back during symmetric lifting. Journal of Biomechanics 102, 109486. https://doi.org/10.1016/j. jbiomech.2019.109486.

Koopman AS, Kingma I, Faber GS, de Looze MP and van Dieën JH (2019) Effects of a passive exoskeleton on the mechanical loading of the low back in static holding tasks. Journal of Biomechanics 83, 97-103. https://doi.org/10.1016/j jbiomech.2018.11.033.

Kothgassner OD, Felnhofer A, Hauk N, Kastenhofer E, Gomm J and Kryspin-Exner I (2013) TUI. Technology Usage Inventory. Vienna: ICARUS.

Latikka R, Turja T and Oksanen A (2019) Self-efficacy and acceptance of robots. Computers in Human Behavior 93, $157-163$. https://doi.org/10.1016/j.chb.2018.12.017.

Lee H, Kim W, Han J and Han C (2012) The technical trend of the exoskeleton robot system for human power assistance. International Journal of Precision Engineering and Manufacturing 13(8), 1491-1497. https://doi.org/10.1007/s12541-0120197-x.

Mara M and Meyer K (forthcoming) Acceptance of autonomous vehicles: An overview of user-specific, car-specific and contextual determinants. In Alvarez I, Jeon M and Riener A (eds), UX Design in the Era of Automated Driving. Berlin: Springer. 
Maurice P, Čamernik J, Gorjan D, Schirrmeister B, Bornmann J, Tagliapietra L, Latella C, Pucci D, Fritzsche L, Ivaldi S and Babič J (2019) Objective and subjective effects of a passive exoskeleton on overhead work. IEEE Transactions on Neural Systems and Rehabilitation Engineering 28(1), 152-164. https://doi.org/10.1109/TNSRE.2019.2945368.

McDonald T and Siegall M (1992) The effects of technological self-efficacy and job focus on job performance, attitudes, and withdrawal behaviors. The Journal of Psychology 126(5), 465-475. https://doi.org/10.1080/00223980.1992.10543380.

Montoya AK (2019) Moderation analysis in two-instance repeated measures designs: Probing methods and multiple moderator models. Behavior Research Methods 51(1), 61-82. https://doi.org/10.3758/s13428-018-1088-6.

Montoya AK and Hayes AF (2017) Two-condition within-participant statistical mediation analysis: A path-analytic framework. Psychological Methods 22(1), 6-27. https://doi.org/10.1037/met0000086.

Motmans R, Debaets T and Chrispeels S (2019) Effect of a passive exoskeleton on muscle activity and posture during order picking. In Bagnara S, Tartaglia R, Albolino S, Alexander T and Fujita Y (eds), Advances in Intelligent Systems and Computing. Proceedings of the 20th Congress of the International Ergonomics Association (IEA 2018) (Vol. 820). Cham: Springer International Publishing, pp. 338-346. https://doi.org/10.1007/978-3-319-96083-8_45.

Peters M and Wischniewski S (2019) The Impact of Using Exoskeletons on Occupational Safety and Health. Discussion Paper. Luxembourg: European Agency for Safety and Health at Work - EU-OSHA.

Rahman MS, Ko M, Warren J and Carpenter D (2016) Healthcare technology self-efficacy (HTSE) and its influence on individual attitude: An empirical study. Computers in Human Behavior 58, 12-24. https://doi.org/10.1016/j.chb.2015.12.016.

Rosen M (2004) Zum Einfluss Beruflicher Selbstwirksamkeitserwartungen Und persönlicher Ziele Auf Beruflichen Erfolg: Eine Empirische Untersuchung Bei Arbeitnehmerinnen Und Arbeitnehmern in Einem mittelständischen Unternehmen. Berlin: Freie Universität Berlin, FB Erziehungswissenschaft und Psychologie.

Rosenthal R, Cooper H and Hedges L (1994) Parametric measures of effect size. The handbook of research synthesis 621(2), 231-244.

Rupal BS, Rafique S, Singla A, Singla E, Isaksson M and Virk GS (2017) Lower-limb exoskeletons: Research trends and regulatory guidelines in medical and non-medical applications. International Journal of Advanced Robotic Systems 14(6), 1-27. https://doi.org/10.1177/1729881417743554.

Schade J and Schlag B (2003) Acceptability of urban transport pricing strategies. Transportation Research Part F: Traffic Psychology and Behaviour 6(1), 45-61. https://doi.org/10.1016/S1369-8478(02)00046-3.

Shore L, Power V, Hartigan B, Schülein S, Graf E, de Eyto A and O'Sullivan L (2020) Exoscore: A design tool to evaluate factors associated with technology acceptance of soft lower limb exosuits by older adults. Human Factors 62(3), 391-410. https://doi.org/10.1177/0018720819868122.

Siedl S, Wolf M and Mara M (2021) Exoskeletons in the supermarket: Influences of comfort, strain relief and task-technology fit on retail workers' post-trial intention to use. In Proceedings of the 2021 ACM/IEEE International Conference on Human-Robot Interaction. New York: ACM. https://doi.org/10.1145/3434074.3447200.

Smets M (2019) A field evaluation of arm-support exoskeletons for overhead work applications in automotive assembly. IISE Transactions on Occupational Ergonomics and Human Factors 7(3-4), 192-198. https://oi.org/10.1080/ 24725838.2018.1563010.

Spada S, Ghibaudo L, Gilotta S, Gastaldi L and Cavatorta MP (2017) Investigation into the applicability of a passive upper-limb exoskeleton in automotive industry. Procedia Manufacturing 11, 1255-1262. https://doi.org/10.1016/j.promfg.2017.07.252.

Steinhilber B, Luger T, Schwenkreis P, Middeldorf S, Bork H, Mann B, von Glinski A, Schildhauer TA, Weiler S, Schmauder M, Heinrich K, Winter G, Schnalke G, Frener P, Schick R, Wischniewski S, Heinrich K (2020). The use of exoskeletons in the occupational context for primary, secondary, and tertiary prevention of work-related musculoskeletal complaints. IISE Transactions on Occupational Ergonomics and Human Factors 8, 1-20. https://doi.org/10.1080/24725838.2020.1844344.

Theurel J, Desbrosses K, Roux T and Savescu A (2018) Physiological consequences of using an upper limb exoskeleton during manual handling tasks. Applied Ergonomics 67, 211-217. https://doi.org/10.1016/j.apergo.2017.10.008.

Toxiri S, Näf MB, Lazzaroni M, Fernández J, Sposito M, Poliero T, Monica L, Anastasi S, Caldwell DG and Ortiz J (2019) Back-support exoskeletons for occupational use: An overview of technological advances and trends. IISE Transactions on Occupational Ergonomics and Human Factors 7(3-4), 237-249. https://doi.org/10.1080/24725838.2019.1626303.

Venkatesh V and Bala H (2008) Technology acceptance model 3 and a research agenda on interventions. Decision Sciences 39(2), 273-315. https://doi.org/10.1111/j.1540-5915.2008.00192.x.

Venkatesh V and Davis FD (2000) A theoretical extension of the technology acceptance model: Four longitudinal field studies. Management Science 46(2), 186-204. https://doi.org/10.1287/mnsc.46.2.186.11926.

Venkatesh V, Morris MG, Davis GB and Davis FD (2003) User acceptance of information technology: Toward a unified view. MIS Quarterly 27, 425-478. https://doi.org/10.2307/30036540.

Venkatesh V, Thong JYL and Xu X (2012) Consumer acceptance and use of information technology: Extending the unified theory of acceptance and use of technology. MIS Quarterly 36(1), 157-178. https://oi.org/10.2307/41410412.

Voilqué A, Masood J, Fauroux JC, Sabourin L and Guezet $\mathbf{O}$ (2019) Industrial exoskeleton technology: Classification, structural analysis, and structural complexity indicator. In 2019 Wearable Robotics Association Conference (WearRAcon). Scottsdale, AZ: IEEE, pp. 13-20. https://doi.org/10.1109/WEARRACON.2019.8719395. 
Sandra M. Siedl, BA, MA, is a Research Associate and PhD candidate at the LIT Robopsychology Lab at the Johannes Kepler University Linz. She received her master's degree in Business Administration and Psychology and her current research deals with human-exoskeleton interaction from a human-centered perspective.

Dr Martina Mara is a Professor of Robopsychology at the Johannes Kepler University Linz, Austria. Her work focuses on humancentered technology development, interdisciplinary research, and psychological aspects of AI and Robotics. She is a member of the Austrian Council for Robotics and AI (ACRAI).

\section{Appendix A}

English items of baseline questionnaire and evaluation questionnaire ${ }^{7}$

Table A1. Task-specific self-efficacy at $\mathrm{t}_{1}\left(T S S E_{\mathrm{t} 1}\right)$ and task-specific self-efficacy at $\mathrm{t}_{2}\left(T S S E_{\mathrm{t} 2}\right)$

\begin{tabular}{|c|c|c|c|c|c|}
\hline \multirow[b]{2}{*}{ tsse pre1: I feel able to perform my job tasks comprehensively } & \multicolumn{3}{|c|}{ Not agree at all } & \multicolumn{2}{|c|}{ Totally agree } \\
\hline & $\square 1$ & $\square 2$ & $\square 3$ & $\square 4$ & $\square 5$ \\
\hline tsse pre2: I am not sure that I have the skills required for my job inverted $(R)$ & $\square 1$ & $\square 2$ & $\square 3$ & $\square 4$ & $\square 5$ \\
\hline tsse_pre3: I know I can meet my job requirements & $\square 1$ & $\square 2$ & $\square 3$ & $\square 4$ & $\square 5$ \\
\hline tsse_pre4: I have confidence in my abilities and can thus calmly face task-related difficulties & $\square 1$ & $\square 2$ & $\square 3$ & $\square 4$ & $\square 5$ \\
\hline tsse_post1: Assisted by the exoskeleton, I feel able to perform my job tasks comprehensively & $\square 1$ & $\square 2$ & $\square 3$ & $\square 4$ & $\square 5$ \\
\hline $\begin{array}{l}\text { tsse_post2: Despite the support of the exoskeleton, I am not sure that I have the skills required } \\
\text { for my job inverted }(R)\end{array}$ & $\square 1$ & $\square 2$ & $\square 3$ & $\square 4$ & $\square 5$ \\
\hline tsse_post3: With the help of the exoskeleton I can meet my job requirements & $\square 1$ & $\square 2$ & $\square 3$ & $\square 4$ & $\square 5$ \\
\hline $\begin{array}{l}\text { tsse_post } 4 \text { : Supported by the exoskeleton, I have confidence in my abilities and can thus } \\
\text { calmly face task-related difficulties }\end{array}$ & $\square 1$ & $\square 2$ & $\square 3$ & $\square 4$ & $\square 5$ \\
\hline
\end{tabular}

Table A2. Usability (Usab), usefulness (Usf), and intention to use (ITU)

\begin{tabular}{|c|c|c|c|c|c|c|c|}
\hline \multirow[b]{2}{*}{ usab_post1: The application of the exoskeleton is easy to understand } & \multicolumn{4}{|c|}{ Not agree at all } & \multicolumn{3}{|c|}{ Very much agree } \\
\hline & $\square 1$ & $\square 2$ & $\square 3$ & $\square 4$ & $\square 5$ & $\square 6$ & $\square 7$ \\
\hline usab_post2: Overall, the use of the exoskeleton is simple & $\square 1$ & $\square 2$ & $\square 3$ & $\square 4$ & $\square 5$ & $\square 6$ & $\square 7$ \\
\hline usab_post3: Using the exoskeleton is complicated inverted $(R)$ & $\square 1$ & $\square 2$ & $\square 3$ & $\square 4$ & $\square 5$ & $\square 6$ & $\square 7$ \\
\hline usf_post1: The use of the exoskeleton would make things more comfortable & $\square 1$ & $\square 2$ & $\square 3$ & $\square 4$ & $\square 5$ & $\square 6$ & $\square 7$ \\
\hline $\begin{array}{l}\text { usf_post } 2 \text { : The exoskeleton would assist me to perform my daily job tasks more } \\
\text { comfortably }\end{array}$ & $\square 1$ & $\square 2$ & $\square 3$ & $\square 4$ & $\square 5$ & $\square 6$ & $\square 7$ \\
\hline usf_post3: If I could afford the exoskeleton, I would get it & $\square 1$ & $\square 2$ & $\square 3$ & $\square 4$ & $\square 5$ & $\square 6$ & $\square 7$ \\
\hline usf_post4: The exoskeleton would support me in carrying out my daily job tasks & $\square 1$ & $\square 2$ & $\square 3$ & $\square 4$ & $\square 5$ & $\square 6$ & a7 \\
\hline itu_post1: I would use the exoskeleton & $\square 1$ & $\square 2$ & $\square 3$ & $\square 4$ & $\square 5$ & $\square 6$ & $\square 7$ \\
\hline itu_post2: I would like the exoskeleton to be purchased & $\square 1$ & $\square 2$ & $\square 3$ & $\square 4$ & $\square 5$ & $\square 6$ & $\square 7$ \\
\hline itu_post3: I would want to have access to the exoskeleton & $\square 1$ & $\square 2$ & $\square 3$ & $\square 4$ & $\square 5$ & $\square 6$ & $\square 7$ \\
\hline
\end{tabular}

Table A3. Perceived physical strain relief (Rel)

\begin{tabular}{llllll}
\hline & \multicolumn{4}{c}{ Hardly any Very much } \\
\hline rel_post: How much strain relief did the system provide? & $\square 1$ & $\square 2$ & $\square 3$ & $\square 4$ & $\square 5$ \\
\hline
\end{tabular}

\footnotetext{
${ }^{7}$ The original language of the items was German. We translated the items into English for accessibility purposes only.

Cite this article: Siedl S. M and Mara M (2021). Exoskeleton acceptance and its relationship to self-efficacy enhancement, perceived usefulness, and physical relief: A field study among logistics workers. Wearable Technologies, 2, e10. doi:https://doi.org/ $10.1017 /$ wtc. 2021.10
} 